\title{
Effects of Resin Content on the Characteristics of Bamboo Oriented Strand Board Prepared from Strands of Betung, Ampel, and Their Mixtures
}

Tengku Muhammad Renzy Hariz ${ }^{1}$, Indra Agus Santosa ${ }^{1}$, Muhammad Iqbal Maulana ${ }^{1}$, Marwanto ${ }^{1}$, Denni Prasetia $^{2}$, Wahyu Hidayat ${ }^{3}$, Muhammad Adly Rahandi Lubis ${ }^{4}$, Nam Hun Kim ${ }^{2, *}$, Fauzi Febrianto ${ }^{1, * *}$

${ }^{1}$ Department of Forest Products, Faculty of Forestry and Environment, IPB University. Jl. Ulin, Kampus IPB Darmaga Bogor, 16680, Bogor, Indonesia

2 Department of Forest Materials Engineering, College of Forest and Environmental Sciences, Kangwon National University. Chuncheon, 24341, Republic of Korea

${ }^{3}$ Department of Forestry, Faculty of Agriculture, University of Lampung. Jl. Sumantri Brojonegoro 1, Bandar Lampung, 35145, Indonesia

${ }^{4}$ Research Center for Biomaterials, National Research and Innovation Agency. Jl. Raya Jakarta-Bogor Km.46, Cibinong, Bogor, 16911, Indonesia

* Corresponding Author. E-mail address: kimnh@kangwoon.ac.kr

${ }^{* *}$ Corresponding Author. E-mail address: febrianto76@yahoo.com

\section{ARTICLE HISTORY}

Received: 15 July 2021

Peer review completed: 9 November 2021

Received in revised form: 14 November 2021 Accepted: 17 November 2021

\section{KEYWORDS:}

Ampel (Bambusa vulgaris) Bamboo oriented strand board Betung (Dendrocalamus asper) Resin content Strand mixtures
(C) 2021 The Author(s). Published by Department of Forestry, Faculty of Agriculture, University of Lampung in collaboration with Indonesia Network for Agroforestry Education (INAFE).

This is an open access article under the CC BY-NC license:

https://creativecommons.org/licenses/by$\mathrm{nc} / 4.0 /$.

\begin{abstract}
The objectives of this research were to evaluate bamboo-oriented strand board (BOSB) characteristics made from betung (Dendrocalamus asper), ampel (Bambusa vulgaris), and their mixtures at two different contents (3\% and $5 \%$ ) of methylene diphenyl di-isocyanate (MDI) adhesives. The strands were steam-treated at $126^{\circ} \mathrm{C}$ for $1 \mathrm{~h}$ under the pressure of $0.14 \mathrm{MPa}$. Three-layered BOSBs with a target density of $0.7 \mathrm{~g} / \mathrm{cm}^{3}$ were made with the size of $30 \mathrm{~cm} \times 30 \mathrm{~cm} \times 0.9 \mathrm{~cm}$ and a shelling ratio of 1:2:1 (face:core:back layers). The physical and mechanical properties of BOSB were evaluated following JIS A 5908 (2003) standard, and the results were compared with the CSA 0437.0 Grade O-1 standard. The results show that BOSB from the mixtures of betung and ampel bamboo strands has higher dimensional stability as shown by the decrease in water absorption and thickness swelling and higher mechanical properties than single BOSB. All BOSBs with 5\% resin content have higher dimensional stability, MOE, and MOR than BOSB with $3 \%$ resin content. The physical and mechanical properties of all BOSB manufactured met the CSA 0437.0 Grade O-1 standard. This study proved that BOSBs from the mixture of betung and ampel strands have the potential to be developed due to having better physical and mechanical qualities than a single BOSB.
\end{abstract}

\section{Introduction}

Bamboo is a commodity with the largest production in Indonesia compared to other nontimber forest products. Bamboo production in Indonesia increased from 9.6 million stems in 2015 to 11.3 million in 2020 (Statistics Indonesia 2016, 2021). Bamboo also belongs to fast-growing species with high mechanical strength parallel to the grain direction and is lighter than wood (Febrianto et al. 2017; Maulana et al. 2021a). Chaowana and Barbu (2017) stated that bamboo has comparable characteristics to wood when applied as a composite product. Using bamboo as a composite material can also be cost-effective and workable in construction (Manandhar et al. 
2019). However, bamboo has low cleavage strength and has a hollow shape (Chaowana and Barbu 2017; Febrianto et al. 2017). These features make it challenging to use bamboo as a solid board with large size. Based on these advantages and disadvantages, bamboo can be used to produce composite panels such as oriented strand board.

Oriented strand board (OSB) is composed of strands arranged perpendicularly between layers and bonded together using an exterior adhesive (APA 2017). This arrangement aims to improve the quality of the panels (APA 2017; Febrianto et al. 2017). Factors that can affect the quality of OSB are the type of raw material, the type and content of adhesive, pre-treatment, extractive substances, shelling ratio, compression ratio, and density profile (Febrianto et al. 2017).

The bamboo species that can be used as bamboo OSB (BOSB) materials are betung (Dendrocalamus asper) and ampel (Bambusa vulgaris) (Davinsy et al. 2019; Febrianto et al. 2015). The characteristics of betung BOSB meet the standards of commercial OSB (Febrianto et al. 2012). However, the use of betung bamboo as BOSB with steam treatment shows better characteristics than untreated (Fatrawana et al. 2019; Maulana et al. 2017, 2019, 2021b, 2021c). On the other hand, the ampel BOSB has lower quality than the betung BOSB (Febrianto et al. 2015) due to higher extractive content in ampel bamboo (Maulana et al. 2020). Previous studies have developed BOSB from single bamboo species (Fatrawana et al. 2019; Febrianto et al. 2012, 2015; Maulana et al. 2017, 2019, 2021c). However, BOSB made from the mixture of betung and ampel bamboo strands has not been reported. Semple et al. (2015) reported that OSB from the mixture of moso bamboo and aspen wood strands produced better mechanical properties than all single OSB and had better dimensional stability than moso bamboo single OSB.

Another factor that can affect the properties of BOSB is the resin content. Several studies have shown that different levels of resin content produce different qualities of BOSB as well. Maulana et al. (2019) reported that increasing the resin content resulted in better physical and mechanical properties of BOSB. Increasing the resin content of methylene diphenyl di-isocyanate (MDI) in the range of 3-5\% resulted in better OSB strength and dimensional stability (Direske et al. 2017). Based on the above explanation, BOSB from the mixture of betung and ampel bamboo with different resin content have the potential to be developed.

\section{Materials and Methods}

\subsection{Strand Preparation and Pre-treatment}

Three-year-old betung and ampel bamboo from Cikereteg, Sukabumi, West Java, was harvested and converted into strands with a targeted length, width, and thickness of $7 \mathrm{~cm}, 2 \mathrm{~cm}$, and $0.05 \mathrm{~cm}$, respectively. The actual strand geometry is shown in Table 1. Strands were sorted according to the target size then air-dried. The strands were then steamed in an autoclave (Gea YX-24LDJ) at $126^{\circ} \mathrm{C}$, under a pressure of $0.14 \mathrm{MPa}$ for $1 \mathrm{~h}$ (Maulana et al. 2017). After steam treatment, strands were air-dried and then oven-dried at $\pm 60^{\circ} \mathrm{C}$ until they reached moisture content (MC) of less than 5\%.

\subsection{Bamboo Oriented Strand Board Manufacturing}

Strands from betung and ampel bamboo were mixed separately with two resin content (3\% and $5 \%$ ) of methylene diphenyl di-isocyanate (MDI). The mixing was carried out using a spray gun in a rotary drum blender. Approximately $1 \%$ of paraffin wax was added to the mixture of 
strand and adhesive. BOSBs with a target density of $0.7 \mathrm{~g} / \mathrm{cm}^{3}$ were manufactured with a size of $30 \mathrm{~cm} \times 30 \mathrm{~cm} \times 0.9 \mathrm{~cm}$ and a layer ratio of 1:2:1. The three layers of BOSB are arranged perpendicularly between layers. Board were made in several combinations i.e.: AAA (ampel, ampel, ampel), BBB (betung, betung, betung), ABA (ampel, betung, ampel), and BAB (betung, ampel, betung). The board was then hot-pressed at a temperature of $160^{\circ} \mathrm{C}$ and a pressure of 2.45 $\mathrm{MPa}$ for $9 \mathrm{~min}$. The compressed board was then conditioned for \pm 14 days at room temperature with a relative humidity of $60 \%$ to achieve equilibrium $\mathrm{MC}$ and eliminate residual stresses.

Table 1. Geometric characteristics of betung and ampel bamboo strands

\begin{tabular}{clccc}
\hline $\begin{array}{c}\text { Bamboo } \\
\text { strand }\end{array}$ & \multicolumn{1}{c}{ Parameters } & Average & Minimum & Maximum \\
\hline \multirow{5}{*}{ Betung } & Length $(\mathrm{cm})$ & 6.40 & 5.53 & 7.47 \\
& Width $(\mathrm{cm})$ & 2.17 & 1.70 & 2.65 \\
& Thickness $(\mathrm{cm})$ & 0.09 & 0.05 & 0.16 \\
& Aspect ratio & 2.97 & 2.40 & 4.32 \\
& Slenderness ratio & 73.76 & 38.38 & 128.80 \\
\hline \multirow{3}{*}{ Ampel } & Length $(\mathrm{cm})$ & 6.27 & 5.32 & 6.75 \\
& Width $(\mathrm{cm})$ & 2.09 & 1.60 & 2.54 \\
& Thickness $(\mathrm{cm})$ & 0.09 & 0.05 & 0.20 \\
& Aspect ratio & 3.02 & 1.10 & 3.84 \\
& Slenderness ratio & 71.03 & 23.20 & 127.20 \\
\hline
\end{tabular}

Note: Determined by measuring 100 strands selected randomly.

\subsection{Testing Procedure}

The physical and mechanical properties of BOSB were evaluated following JIS A 5908 standard (JSA 2003), and the results were compared to CSA 0437.0 (Grade O-1) standard. The physical properties tested included density, water absorption, and thickness swelling after $24 \mathrm{~h}$ soaked in water. The mechanical properties tested included modulus of elasticity, modulus of rupture, and internal bonding strength.

\subsubsection{Density}

The testing samples of $10 \mathrm{~cm} \times 10 \mathrm{~cm} \times 0.9 \mathrm{~cm}$ (length $\times$ width $\times$ thickness) were measured in an air-dried state to obtain its volume $(\mathrm{Va})$. The samples in an air-dried state were then weighed to obtain their weight $(W a)$. Finally, the density $(D)$ value was calculated as follows:

$$
D\left(\mathrm{~g} / \mathrm{cm}^{3}\right)=\frac{W a}{V a}
$$

\subsubsection{Water absorption}

The testing samples having a dimension of $5 \mathrm{~cm} \times 5 \mathrm{~cm} \times 0.9 \mathrm{~cm}$ (length $\times$ width $\times$ thickness) were weighed in an air-dried state $(W 1)$. Then, the samples were soaked for $24 \mathrm{~h}$, drained, and weighed again $(W 2)$. The water absorption $(W A)$ value was calculated using equation 2.

$$
W A(\%)=\frac{W 2-W 1}{W 1} \times 100 \%
$$




\subsubsection{Thickness swelling}

The testing samples of $5 \mathrm{~cm} \times 5 \mathrm{~cm} \times 0.9 \mathrm{~cm}$ (length $\times$ width $\times$ thickness) were measured for their average thickness (T1) and then soaked for $24 \mathrm{~h}$. After soaking, samples were drained, and the average thickness was measured again (T2). The thickness swelling (TS) value was calculated as follows:

$$
T S(\%)=\frac{T 2-T 1}{T 1} \times 100 \%
$$

\subsubsection{Modulus of elasticity}

The modulus of elasticity (MOE) was evaluated using the testing samples of $20 \mathrm{~cm} \times 5 \mathrm{~cm}$ $\times 0.9 \mathrm{~cm}$ (length $\times$ width $\times$ thickness). The test was conducted on parallel and perpendicular to the grain directions with a span length of 15 times of thickness using Instron Universal Testing Machine with a load speed of $10 \mathrm{~mm} / \mathrm{min}$. The MOE value was calculated using equation 4.

$$
\operatorname{MOE}(M P a)=\frac{\Delta P L^{3}}{4 \Delta Y b h^{3}}
$$

where $\Delta P$ is the load under proportion limit $(\mathrm{N}), L$ is span length $(\mathrm{mm}), \Delta Y$ is deflection $(\mathrm{mm}), b$ is sample width (mm), and $h$ is sample thickness $(\mathrm{mm})$.

\subsubsection{Modulus of rupture}

The modulus of rupture (MOR) was tested together with the MOE evaluation. The loading during the MOR test was continued until the sample was broken. The MOR value was calculated using equation 5 .

$$
\operatorname{MOR}(M P a)=\frac{3 P L}{2 b h^{2}}
$$

where $P$ is the maximum load $(\mathrm{N}), L$ is span length $(\mathrm{mm}), b$ is sample width $(\mathrm{mm})$, and $h$ is sample thickness (mm).

\subsubsection{Internal bonding strength}

The testing samples of $5 \mathrm{~cm} \times 5 \mathrm{~cm} \times 0.9 \mathrm{~cm}$ (length $\times$ width $\times$ thickness) were glued to two wooden blocks with epoxy adhesive, then allowed to dry for $24 \mathrm{~h}$. The two blocks were pulled perpendicular to the sample's surface at a $2 \mathrm{~mm} / \mathrm{min}$ loading speed until reaching a maximum load. The internal bonding (IB) strength value was calculated using the following formula:

$$
I B(M P a)=\frac{P}{b l}
$$

where $l$ is sample length (mm).

\subsection{Data Analysis}

The factorial completely randomized design with two factors, namely resin content ( $3 \%$ and $5 \%$ ) and bamboo strand combination (AAA, BBB, ABA, and BAB), were used to analyze data. The analysis of variance (ANOVA) was tested at a 99\% confidence interval. Then Duncan's Multiple Range Test was carried out to find out the levels that were significantly different. All data analyses were carried out using IBM SPSS Statistics 26 Software. 


\section{Results and Discussion}

\subsection{Density}

The BOSBs manufactured reached the target density ranging from $0.72-0.75 \mathrm{~g} / \mathrm{cm}^{3}$ (Fig.1). The results of ANOVA $(\alpha=0.01)$ showed that the resin content and the combination of bamboo strands did not have a significant effect on the density of BOSB. Previous studies showed that betung and ampel BOSBs could achieve a target density of $0.7 \mathrm{~g} / \mathrm{cm}^{3}$ (Fatrawana et al. 2019; Febrianto et al. 2012, 2015; Ibrahim and Febrianto 2013; Maulana et al. 2017, 2019, 2021c). In addition, the difference in BOSB resin content also did not affect the density of the resulting board (Febrianto et al. 2015; Maulana et al. 2019). This shows that the combination of betung and ampel bamboo strands at different resin content could produce BOSB with a homogeneous density. Inhomogeneous BOSB density will result in different boards' dimensional stability and mechanical strength (Maulana et al. 2021d).

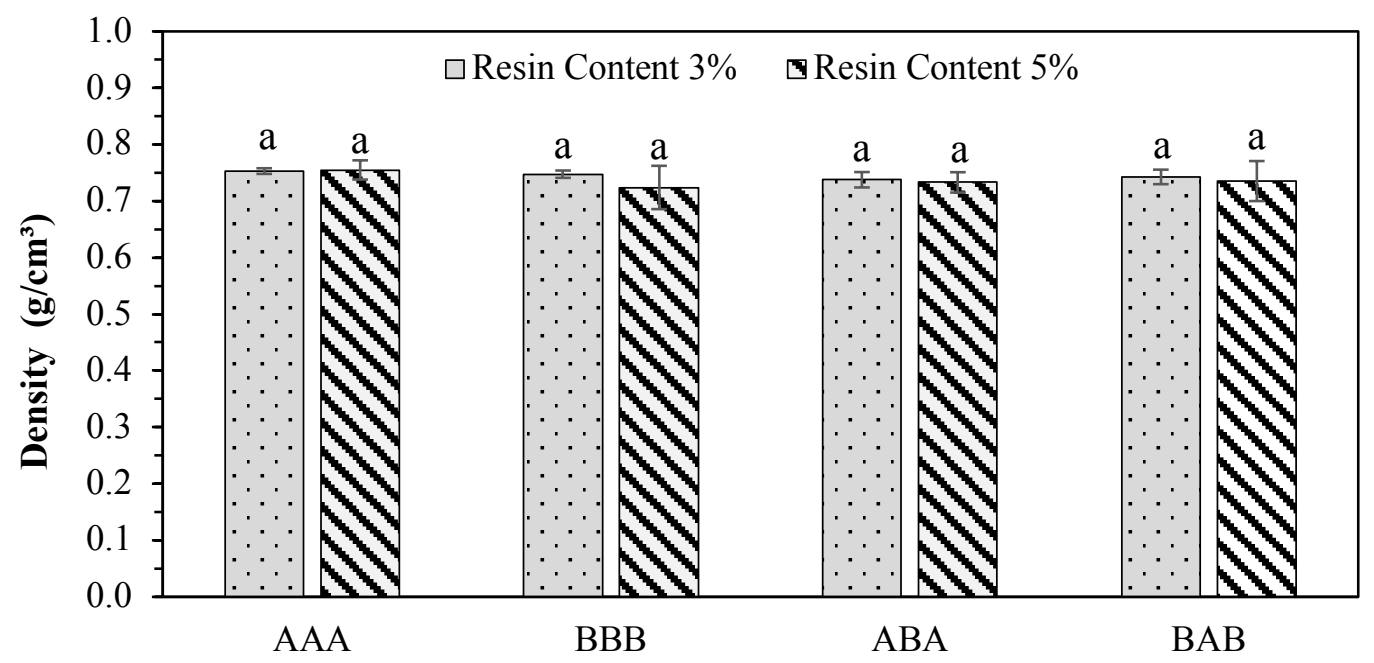

\section{Bamboo strand combination}

Fig. 1. Density values of BOSB with different resin content (Notes: different letters showed a significant difference).

\subsection{Water Absorption}

The water absorption (WA) values for $24 \mathrm{~h}$ of the BOSBs ranged from 24.12-33.62\% (Fig. 2). The highest WA value was obtained by AAA BOSB with $3 \%$ resin content, while AAA BOSB with $5 \%$ resin content has the lowest value. The results of ANOVA $(\alpha=0.01)$ showed that the interaction between the two factors had a significant effect on the $24 \mathrm{~h}$ WA value of BOSB. Duncan's Multiple Range Test showed that AAA BOSB with 3\% resin content was significantly different from AAA BOSB with 5\% resin content. Meanwhile, WA of single BOSB and mixed BOSB at $3 \%$ and $5 \%$ resin content was not significantly different.

In general, the WA value of BOSB with $5 \%$ resin content is lower than BOSB with $3 \%$ resin content. Previous studies showed that increasing resin content reduced the WA of BOSB (Febrianto et al. 2015; Maulana et al. 2019). This is because the increase in resin content could penetrate and fill more BOSB cavities (Barbuta et al. 2011; Febrianto et al. 2017). On the other hand, the diameter of the vessel and parenchyma of betung bamboo is larger than that of ampel bamboo (Maulana 2019) so that the space to fill BBB BOSB is broader than that of AAA BOSB at $5 \%$ resin content. However, Fig. 2 shows that the WA value of mixed BOSB tends to be lower 
than BBB BOSB. These results proved that the water absorption capacity of BOSB from betung could be minimized by mixing with ampel strands.

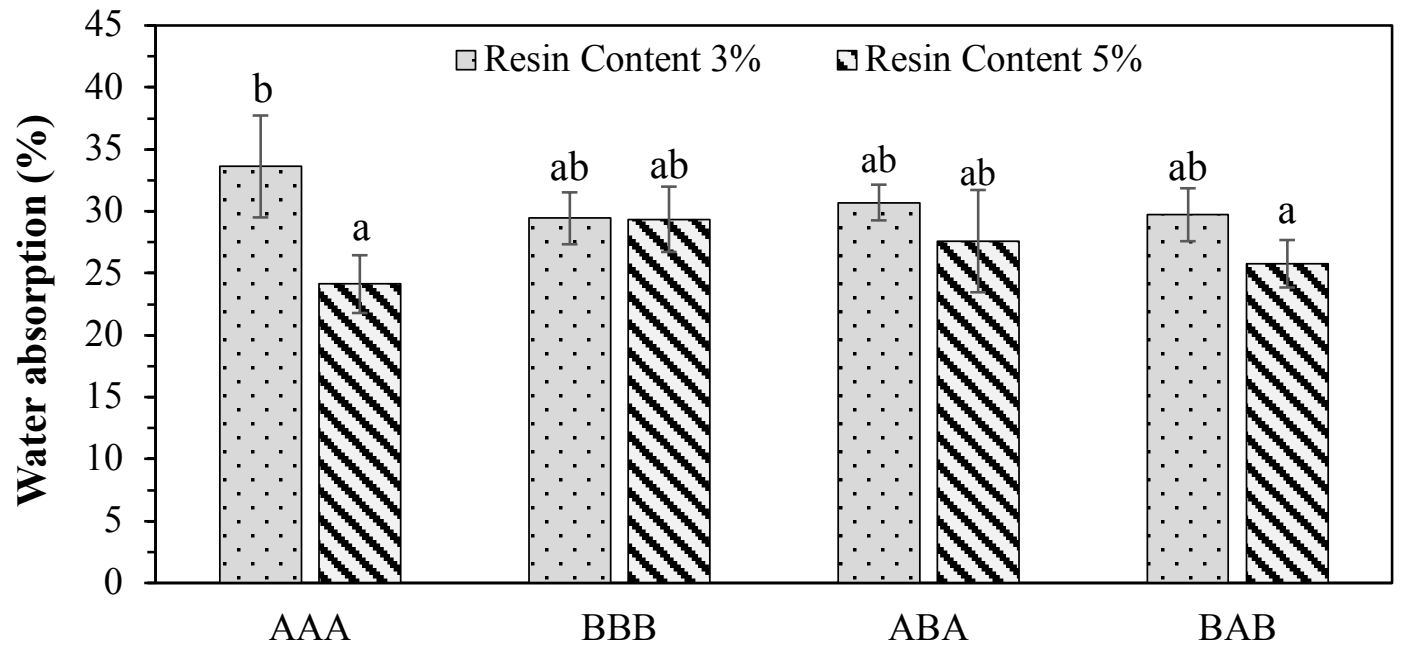

Bamboo strand combination

Fig. 2. The WA values of BOSB with different resin content (Notes: different letters showed a significant difference).

\subsection{Thickness Swelling}

The value of $24 \mathrm{~h}$ thickness swelling (TS) of the BOSB manufactured ranged from 8.22 $13.47 \%$ (Fig. 3). The highest TS value was obtained by AAA BOSB with a resin content of 3\%, while BAB BOSB with 5\% resin content has the lowest value. The results of ANOVA $(\alpha=0.01)$ showed that the interaction of the two factors had a significant effect on TS BOSB value. In addition, the results of Duncan's Multiple Range Test showed that TS values were significantly different in each BOSB with 3\% resin content.

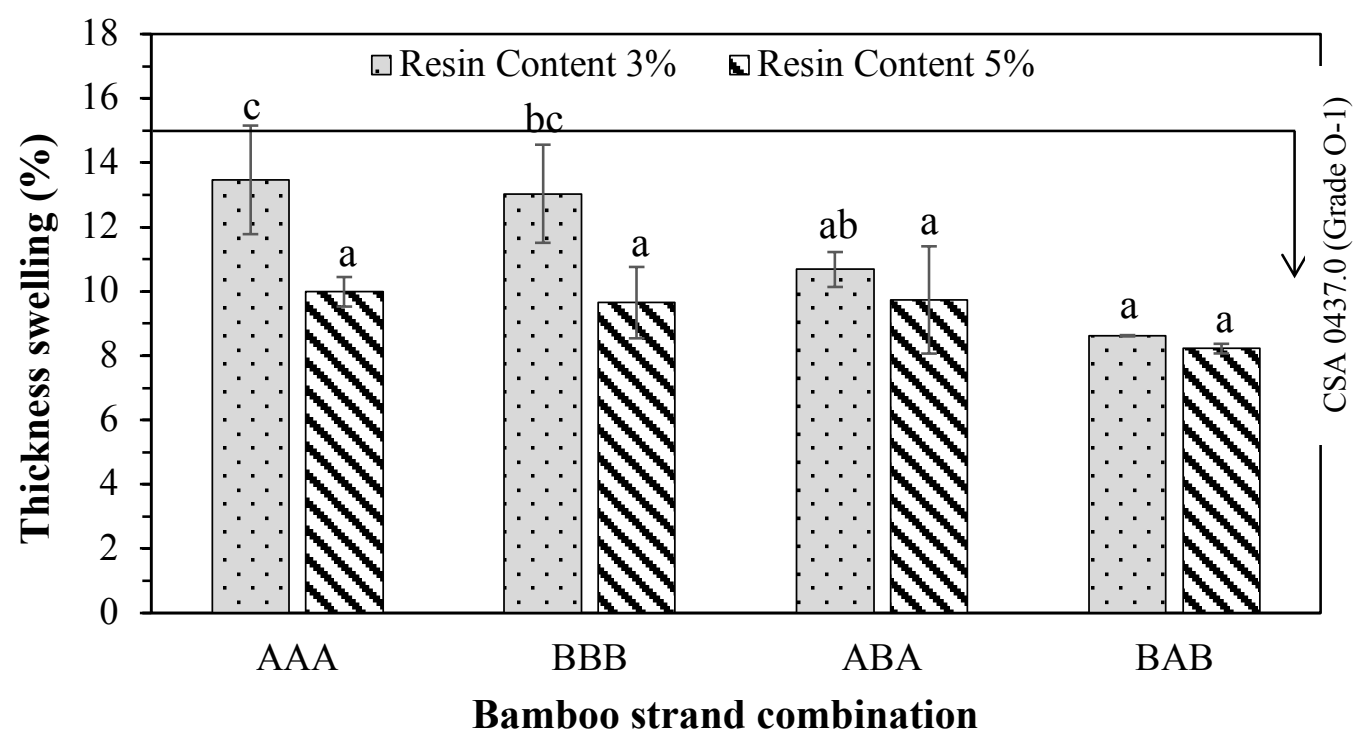

Fig. 3. The TS values of BOSB with different resin content (Notes: different letters showed a significant difference).

The value of TS BOSB with 5\% resin content was lower than BOSB with 3\% resin content. Previous studies showed that increasing resin content reduced TS of BOSB (Febrianto et al. 2015; 
Maulana et al. 2019). In addition, higher resin content resulted in higher bonding strength between strands so that the dimensions became more stable (Febrianto et al. 2015). Fig. 3 shows that the TS value of mixed BOSB was lower than that of a single BOSB for each bamboo species. Semple et al. (2015) showed that mixing two raw materials to produce OSB could increase the board's dimensional stability. In general, the TS value of all BOSBs met the CSA 0437.0 standard (Grade O-1).

\subsection{Modulus of Elasticity}

Modulus of elasticity (MOE) shows the ratio between stress and strain below the elastic limit so that the object will return to the original bend at the load limit (Mardikanto et al. 2017). The MOE parallel to the grain direction of BOSB manufactured ranged from 5,744-11,955 MPa (Fig. 4). The highest MOE parallel to the grain direction was obtained by BAB BOSB with a resin content of $5 \%$, while AAA BOSB with $3 \%$ resin content has the lowest value. The MOE perpendicular to the grain direction of the BOSB manufactured ranged from 1,511-3,474 $\mathrm{MPa}$ (Fig. 5). The highest MOE perpendicular to the grain direction was obtained by ABA BOSB with $5 \%$ resin content, while AAA BOSB with $3 \%$ resin content has the lowest value. The results of ANOVA $(\alpha=0.01)$ showed that the interaction of the two factors had a significant effect on the values of MOE parallel and perpendicular to the grain directions. The results of Duncan's Multiple Range Test showed a significant difference in each BOSB.

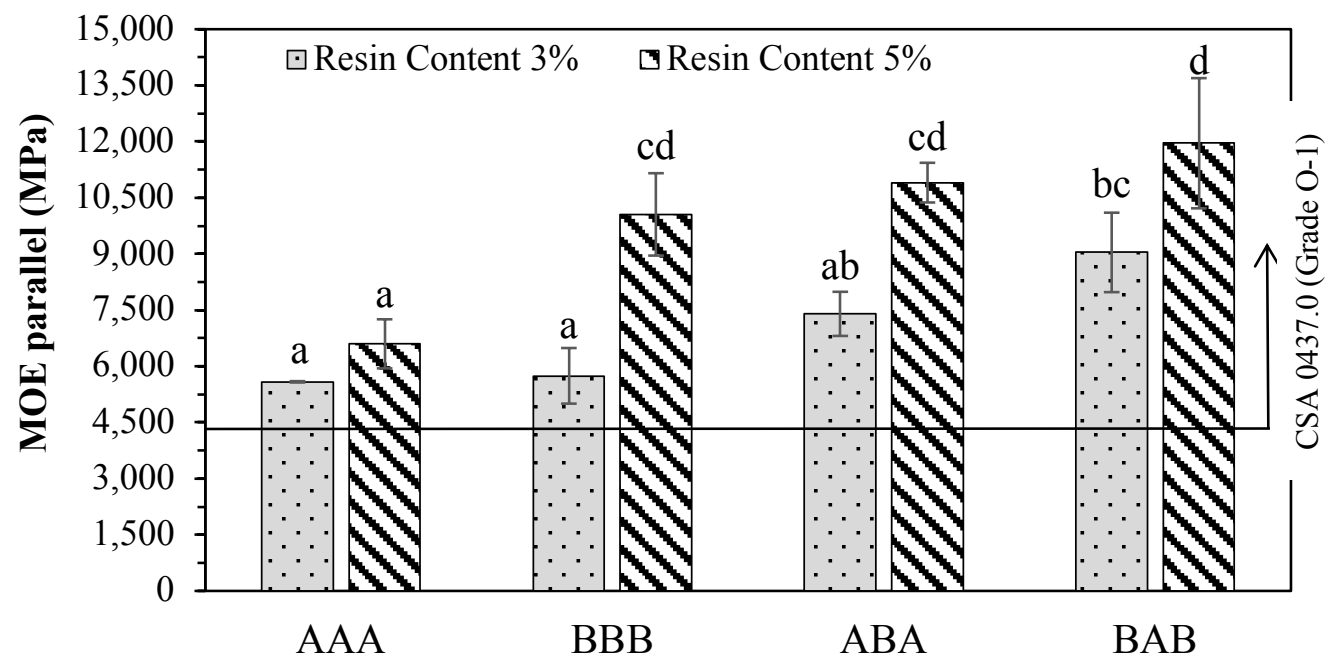

Bamboo strand combination

Fig. 4. MOE parallel to the grain values of BOSB with different resin content (Notes: different letters showed a significant difference).

The MOE parallel and perpendicular to the grain directions at 5\% resin content were higher than 3\% resin content in each BOSB. Gündüz et al. (2011) also reported that increasing the resin content from $3 \%$ to $6 \%$ increased the MOE parallel and perpendicular to the grain directions of BOSB. Stoeckel et al. (2013) reported that adhesives could increase the bond between fibers in their application to lignocellulosic materials. The resin content of 5\% formed more bonds between strands, thereby increasing the stiffness of the BOSB and increasing the MOE value. Fig. 4 shows that mixed BOSB had a better MOE parallel to the grain direction than the single BOSB. The BAB BOSB has a higher MOE perpendicular to the grain direction than ABA BOSB. This is due to Betung bamboo having better mechanical characteristics in some parameters than ampel bamboo 
(Damayanti et al. 2019). This causes the mechanical strength perpendicular to the grain from BOSB with betung bamboo as the core is higher either as a single board or a mixture. Overall, the MOE parallel and perpendicular to the grain directions of BOSB met the CSA 0437.0 (Grade O1) standard.

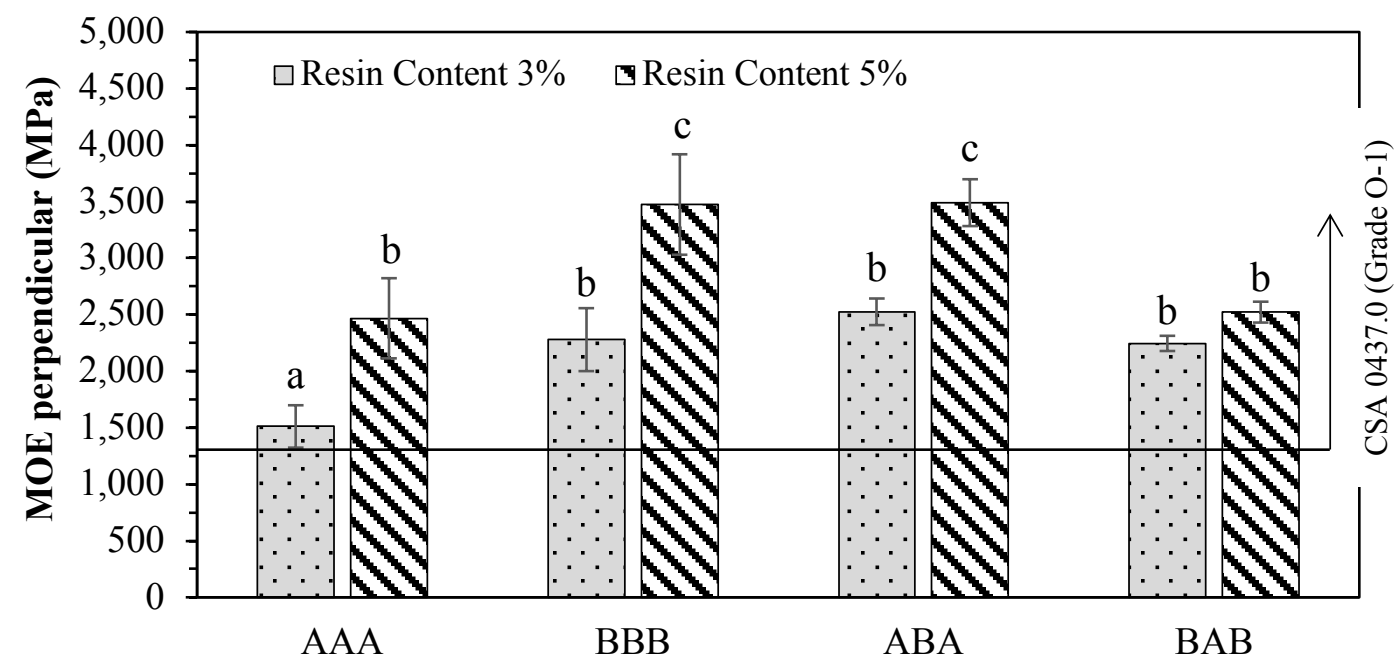

Bamboo strand combination

Fig. 5. MOE perpendicular to the grain values of BOSB with different resin content (Notes: different letters showed a significant difference).

\subsection{Modulus of Rupture}

Modulus of rupture (MOR) is a quantity that indicates the resistance of the material in withstanding deflection caused by shear force (Mardikanto et al. 2017). The MOR parallel to the grain direction of BOSB manufactured ranged from 25-80 MPa (Fig. 6). The highest MOR parallel to the grain direction was obtained by BAB BOSB with a resin content of 5\%, while AAA BOSB with $3 \%$ resin content has the lowest value. The MOR perpendicular to the grain direction of the BOSB obtained ranged from 15-43 MPa (Fig. 7). The highest MOR perpendicular to the grain direction was obtained by BBB BOSB with 5\% resin content, while AAA BOSB with 3\% resin content has the lowest value. The results of ANOVA $(\alpha=0.01)$ showed that the interaction of the two factors significantly affected the values of MOR parallel and perpendicular to the grain directions of BOSB. Duncan's Multiple Range Test results showed that MOR tended to be significantly different in each BOSB.

The MOR values in parallel and perpendicular to the grain directions with $5 \%$ resin content were higher than those with 3\% resin content. Previous studies showed a higher MOR value of BOSB along with an increase in resin content (Febrianto et al. 2015; Maulana et al. 2019). These results showed that the mixed betung and ampel BOSB had better values of MOR parallel to the grain directions than single ampel BOSB. The BBB BOSB also has higher values of MOR parallel and perpendicular to the grain directions than AAA BOSB. This is due to the mechanical properties of the material, which are influenced by fiber length and vascular tissue size (Nuryatin 2012). Betung bamboo has longer fibers than ampel bamboo (Damayanti et al. 2019). Overall, the MOR parallel and perpendicular to the grain directions of BOSB met the CSA 0437.0 (Grade O-1) standard. 


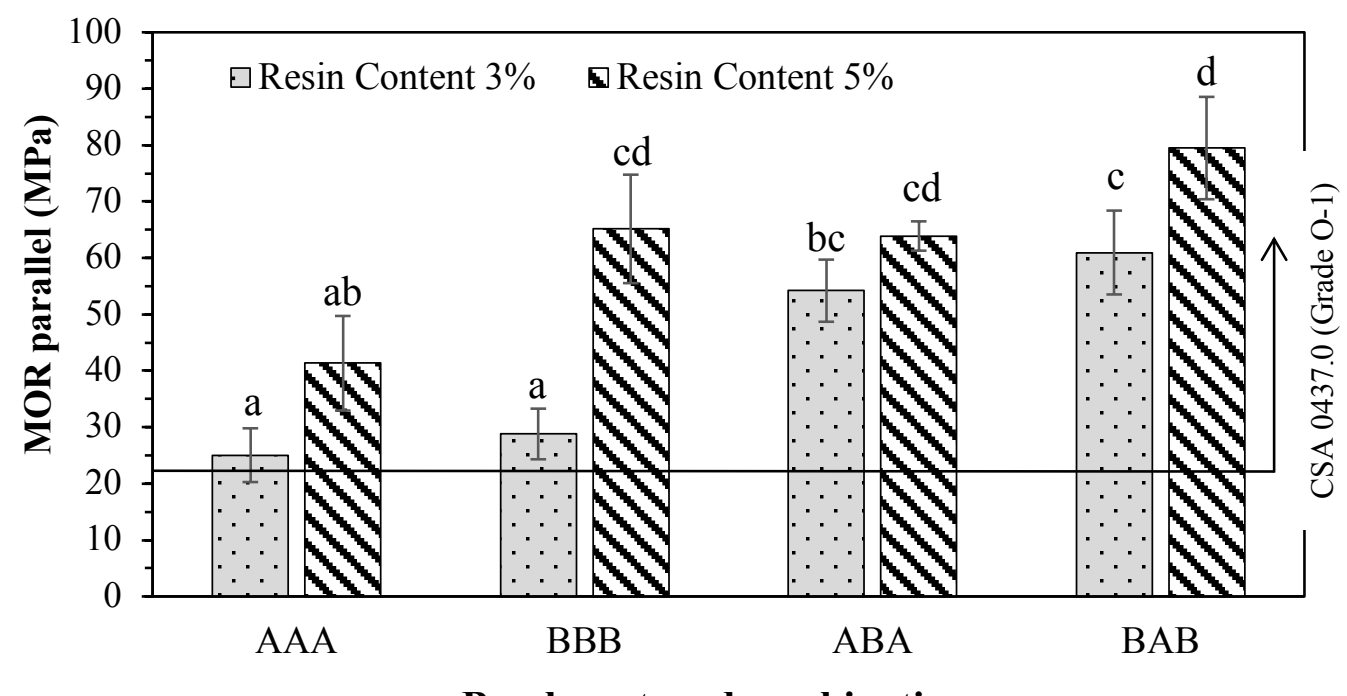

Bamboo strand combination

Fig. 6. MOR parallel to the grain values of BOSB with different resin content (Notes: different letters showed a significant difference).

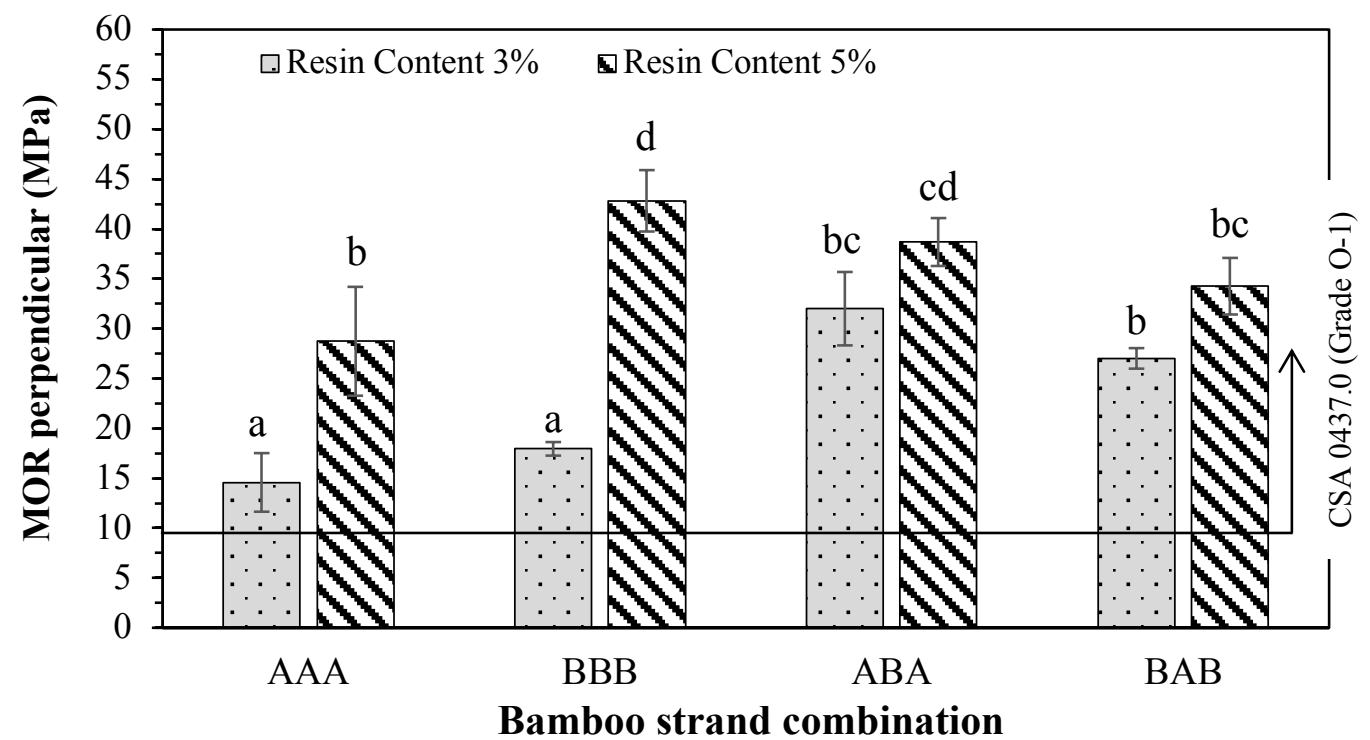

Fig. 7. MOR perpendicular to the grain values of BOSB with different resin content (Notes: different letters showed a significant difference).

\subsection{Internal Bonding Strength}

The internal bonding (IB) strength values of BOSB obtained ranged from $0.48-0.63 \mathrm{MPa}$ (Fig. 8). The highest IB value was obtained by BBB BOSB with a resin content of $5 \%$, while AAA BOSB with $3 \%$ and $5 \%$ resin content has the lowest value. The IB value of BBB and ABA BOSB with $5 \%$ resin content has the highest value than $3 \%$ resin content. However, the results of ANOVA $(\alpha=0.01)$ showed that the differences were not significant. Increasing resin content from $3 \%$ to $5 \%$ has not been able to increase the IB values significantly. Therefore, a higher MDI content is needed to significantly increase the IB value of the BOSB combination of betung and ampel bamboo strands. Previous studies show that the increase in resin content results in better bonding between materials so that it is positively correlated with the IB value (Hong et al. 2017). Fig. 8 also shows that mixtures BOSB tends to have a higher IB value than single ampel BOSB but lower 
than single betung BOSB. This is due to variations of bamboo species density (Maulana 2019; Park et al. 2021) that affected the distribution of the adhesive (Febrianto et al. 2015, 2017; Maulana et al. 2021d). In general, the IB value of all BOSB in each mixture combination and resin content met the CSA 0437.0 (Grade O-1) standard.

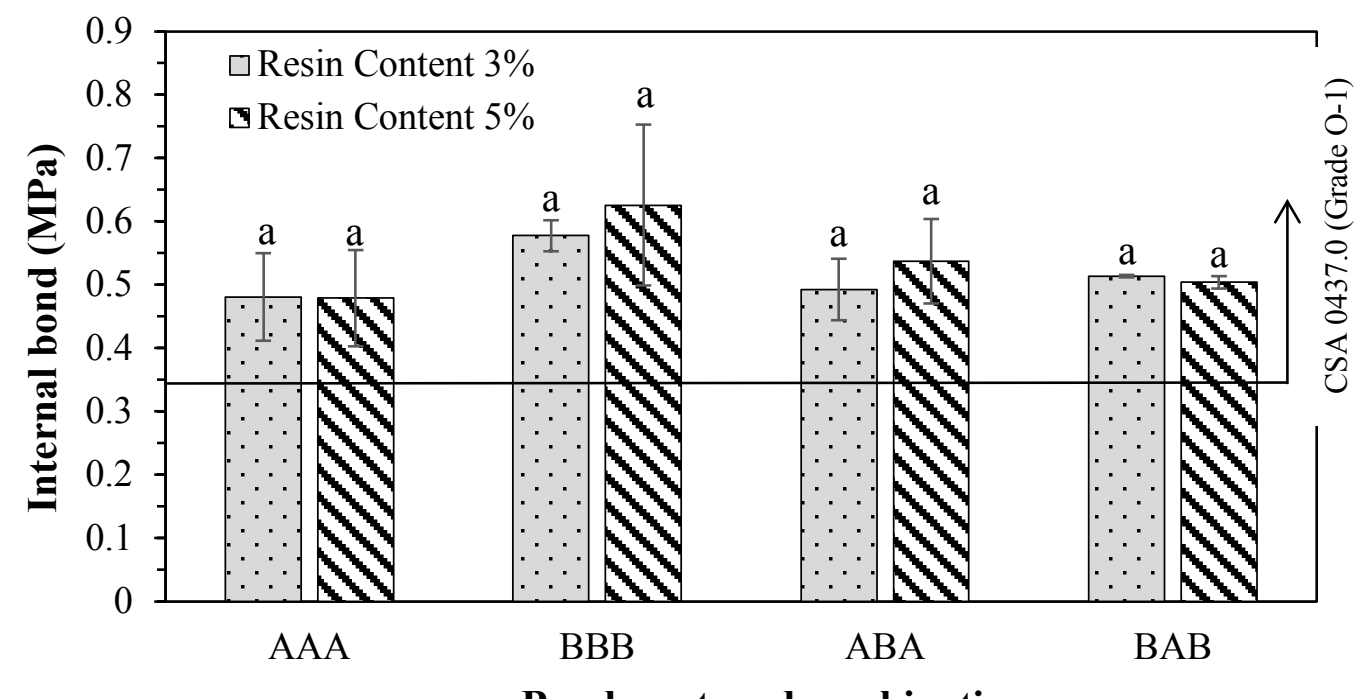

Bamboo strand combination

Fig. 1. IB strength values of BOSB with different resin content (Notes: different letters showed a significant difference).

\section{Conclusions}

The BOSB prepared with mixed bamboo in this study show better physical and mechanical properties than BOSB with single raw materials. The mixed BOSB also has higher dimensional stability than single BOSB, which is indicated by the lower $24 \mathrm{~h}$ WA and TS values. In addition, the $24 \mathrm{~h}$ TS value for each BOSB with 5\% resin content was higher than BOSB with $3 \%$ resin content. The ABA BOSB has higher mechanical strength than single BOSBs. All BOSBs with 5\% resin content had higher physical and mechanical properties than $3 \%$ resin content. The IB value for each BOSB was not significantly different. All BOSBs met CSA 0437.0 (Grade O-1) standards.

\section{Acknowledgments}

This research was supported by the Ministry of Research and Technology/National Research and Innovation Agency of Indonesia through Basic Research (2039/IT3.L1/PN/2021) and WCR (No. 2345/IT3.L1/PN/2021) grants.

\section{References}

APA. 2017. Oriented Strand Board. American Plywood Association. The Engineer Wood Association. Washington, D.C.

Chaowana, P., and Barbu, M. C. 2017. Bamboo: Potential Material for Biocomposites. Ed(s): M. Jawaid, P. M. Tahir, N. Saba, In Woodhead Publishing Series in Composites Science and Engineering, Lignocellulosic Fibre and Biomass-Based Composite Materials. Woodhead Publishing. Sawston, Cambridge. DOI: 10.1016/b978-0-08-100959-8.00013-5

Damayanti, R., Jasni, Sulastiningsih, I. M., Djarwanto, Suprapti, S., Pari, G., Basri, E., 
Komarayati, S., and Abdurahman. 2019. Atlas Bambu Indonesia 1. IPB Press, Bogor.

Davinsy, R., Satria, E. D., Maulana, M. I., Nawawi, D. S., Sari, R. K., Maulana, S., Hidayat, W., and Febrianto, F. 2019. Sifat Fisis dan Mekanis Oriented Strand Board Hibrida Bambu pada Berbagai Shelling Ratio. Jurnal Ilmu dan Teknologi Kayu Tropis 17(2): 152-159. DOI: $10.51850 /$ jitkt.v17i2.473

Direske, M., Bonigut, J., Wenderdel, C., Scheiding, W., and Krug, D. 2017. Effect of MDI Content on Properties of Thermally Treated Oriented Strand Board (OSB). European Journal of Wood and Wood Products 76(3): 823-831. DOI: 10.1007/s00107-017-1256-X

Fatrawana, A., Maulana, S., Nawawi, D. S., Sari, R. K., Hidayat, W., Park, S. H., Febrianto, F., Lee, S. H., and Kim, N. H. 2019. Changes in Chemical Components of Steam-Treated Betung Bamboo Strands and Their Effects on the Physical and Mechanical Properties of Bamboo-Oriented Strand Boards. European Journal of Wood and Wood Products 7(5): 731739. DOI: $10.1007 / \mathrm{s} 00107-019-01426-7$

Febrianto, F., Jang, J. H., Lee, S. H., Santosa, I. A., Hidayat, W., Kwon, J. H., and Kim, N. H. 2015. Effect of Bamboo Species and Resin Content on Properties of Oriented Strand Board prepared from Steam Treated Bamboo Strand. BioResources 10(2): 2642-2655. DOI: 10.15376/biores. 10.2.2642-2655

Febrianto, F., Sahroni, Hidayat, W., Bakar, E. S., Kwon, G., Kwon, J. H., Hong, S. I., and Kim, N. H. 2012. Properties of Oriented Strand Board made from Betung Bamboo (Dendrocalamus asper (Schultes. f) Backer ex Heyne). Wood Science and Technology 46: 53-62. DOI: 10.1007/s00226-010-0385-8

Febrianto, F., Sumardi, I., Hidayat, W., and Maulana, S. 2017. Papan Untai Bambu Berarah: Material Unggul untuk Komponen Bahan Bangunan Struktur. IPB Press. Bogor, Indonesia. Gündüz, G., Yapici, F., Özcicfi, A., and Kalaycioğlu, H. 2011. The Effect of Adhesive Ratio and Pressure Time on Some Properties of Oriented Strand Board. BioResources 6(2): 2118-2124. DOI: 10.15376/biores.6.2.2118-2124

Hong, M. K., Lubis, M. A. R., and Park, B. D. 2017. Effect of Panel Density and Resin Content on Properties of Medium Density Fiberboard. Journal of the Korean Wood Science and Technology 45(4): 444-455. DOI: 10.5658/wood.2017.45.4.444

Ibrahim, M. A., and Febrianto, F. 2013. Properties of Oriented Strand Board (OSB) made from Mixing Bamboo. APRN Journal of Science and Technology 3(9): 937-962.

JSA. 2003. JIS A 5908: Japanese Industrial Standard: Particle Board. Japanese Standard Association (JSA). Tokyo, Japan.

Manandhar, R., Kim, J. H., and Kim, J. T. 2019. Environmental, Social, and Economic Sustainability of Bamboo and Bamboo-Based Construction Materials in Building. Journal of Asian Architecture and Building Engineering 18(2): 49-59. DOI: 10.1080/13467581.2019.1595629

Mardikanto, T. R., Karlinasari, L., and Bahtiar, E. T. 2017. Sifat Mekanis Kayu. IPB Press. Bogor, Indonesia.

Maulana, M. I. 2019. Basic Properties of Seven Bamboo Species for Nanocellulose Production. Thesis. IPB University. Bogor, Indonesia.

Maulana, M. I., Jeon, W. S., Purusatama, B. D., Nawawi, D. S., Nikmatin, S., Sari, R. K., Hidayat, W., Febrianto, F., Kim, J. H., Lee, S. H., Kim, N. H. 2021a. Variation of Anatomical Characteristics within the Culm of the Three Gigantochloa Species from Indonesia. BioResources 16(2): 3596-3606. DOI: 10.15376/biores.16.2.3596-3606 
Maulana, M. I., Marwanto, Nawawi, D. S., Nikmatin, S., Febrianto, F., and Kim, N. H. 2020. Chemical Components Content of Seven Indonesian Bamboo Species. IOP Conference Series: Material Science and Engineering 935: 012028. DOI: 10.1088/1757899x/935/1/012028

Maulana, M. I., Murda, R. A., Purusatama, B. D., Sari, R. K., Nawawi, D. S., Nikmatin, S., Hidayat, W., Lee, S. H., Febrianto, F., and Kim, N. H. 2021b. Effect of Alkali-Washing at Different Concentration on the Chemical Compositions of the Steam Treated Bamboo Strands. Journal of the Korean Wood Science and Technology 49(1): 14-22. DOI: 10.5658/wood.2021.49.1.14

Maulana, M. I., Murda, R. A., Purusatama, B. D., Sari, R. K., Nawawi, D. S., Nikmatin, S., Hidayat, W., Lee, S. H., Febrianto, F., and Kim, N. H. 2021c. Properties of Oriented Strand Board from Alkali-Washed Bamboo Strands after Steam Treatment. BioResources 16(1): 987-996. DOI: 10.15376/biores.16.1.987-996

Maulana, S., Abdillah, I. B., Fatrawana, A., Hidayat, W., Sari, R. K., Sumardi, I., Wistara, N. J., Lee, S. H., Kim, N. H, and Febrianto, F. 2017. Effect of Steam Treatment on Physical and Mechanical Properties of Bamboo Oriented Strand Board. Journal of the Korean Wood Science and Technology 45(6): 872-882. DOI: 10.5658/wood.2017.45.6.872

Maulana, S., Gumelar, Y., Fatrawana, A., Maulana, M. I., Hidayat, W., Sumardi, I., Wistara, N. J., Lee, S. H., Kim, N. H., and Febrianto, F. 2019. Destructive and Non-Destructive Tests of Bamboo Oriented Strand Board under Various Shelling Ratios and Resin Contents. Journal of the Korean Wood Science and Technology 47(4):519-532. DOI: 10.5658/wood.2019.47.4.519

Maulana, S., Hidayat, W., Sumardi, I., Wistara, N. J., Maulana, M. I., Kim, J. H., Lee, S. H., Kim, N. H., and Febrianto, F. 2021d. Properties of Dual-Species Bamboo-Oriented Strand Board Bonded with Phenol Formaldehyde Adhesive under Various Compression Ratios. BioResources 16(3): 5422-5435. DOI: 10.15376/biores.16.3.5422-5435

Nuryatin, N. 2012. Vascular Bundle Pattern as Predictor of Bamboo Utilization. Dissertation. IPB University. Bogor, Indonesia.

Park, S., Lee, M., Febrianto, F., and Wistara, N. J. 2021. Effect on Morphology and Chemical Properties of Indonesian Bamboos by Carbonization. Jurnal Sylva Lestari 9(2): 190-201. DOI: $10.23960 /$ js $129190-201$

Semple, K. E., Zhang, P. K., and Smith, G. D. 2015. Hybrid Oriented Strand Boards made from Moso Bamboo (Phyllostachys pubescens Mazel) and Aspen (Populus tremuloides Michx.): Species-Separated Three-Layer Boards. European Journal of Wood and Wood Products 73(4): 527-536. DOI: 10.1007/s00107-015-0914-0

Statistics Indonesia. 2016. Statistics of Forestry Production 2015. Statistics Indonesia. Jakarta, Indonesia.

Statistics Indonesia. 2021. Statistics of Forestry Production 2020. Statistics Indonesia. Jakarta, Indonesia.

Stoeckel, F., Konnerth, J., and Altmutter, W. G. 2013. Mechanical Properties of Adhesive for Bonding Wood-A Review. International Journal of Adhesion and Adhesives. 45: 32-41. DOI: 10.1016/j.ijadhadh.2013.03.013 